\title{
Ecology and eScience
}

\author{
Christian Mulder
}

\section{Comprehending the gifts of ecology}

Stress ecology, climate change, human well-being, and global sustainability are popular items (Naeem et al. 2009). Given all the challenges in a developing world where the global population is supposed to reach 9.15 billion in 2050 (Pimentel et al. 1999; United Nations Population Division 2010), policy makers are, for the first time, keen on concrete assessments of our world, looking with interest and fear to ecological models. Although the discussion between scientists and politicians is known to be difficult, too many recent catastrophes during a single year - from the British Petroleum oil spill in the Gulf of Mexico (De Gouw et al. 2011) up to the ongoing radioactive Fukushima wreckage (Schiermeier 2011) - rapidly forced a better and constructive interaction between applied ecologists and policy makers at different organization levels. Such an interaction is also reflected by the arising use of internet metrics, blogs, tweets, and social networking - all digital tools that are already more or less linked to the thought process that society and policy are currently going through. Scientists are used to the Web of Science for selecting the appropriate papers, and policy makers are using methodologies for weighing opinions (Bollen et al. 2009). The latter authors even defined modern science as a 'gift economy', and they are absolutely right. What else should happen to improve the interactions between policy and research?

\section{eScience: computation impacted science}

As can be seen in the plethora of data and the huge degree of multidisciplinarity (Figure 1), a full and immediate open access across all disciplines is supposed to be the dream of any eScientist and stakeholder involved in this thought process. At a glance, ecologists should be eScientists par excellence. Most ecological disciplines, in fact, overlap and typically (re)use data from other sciences, which leads to a huge increase in science productivity. Ecology often benefits from methods originally developed for mathematics, physics, and chemistry (Cohen 2004; Elser 2006) and

Correspondence: christian.mulder@rivm.nl

National Institute for Public Health and the Environment (RIVM), Antonie van Leeuwenhoeklaan 9, Bilthoven, 3720 BA, The Netherlands might even benefit from models used in the worlds of informatics and finance (Allesina and Pascual 2009; Haldane and May 2011, respectively). Opposite flows occur as well, from ecological knowledge to archaeology and urban systems, toxicology, and medicine (Sjögren and Lamentowicz 2008; Grimm et al. 2000; Van Straalen 2003; $\mathrm{Zu}$ Dohna et al. 2009, respectively). Ecology is a perfect eScience, and I believe that no scientific discipline has already so many examples of mutual benefits as all ecological (sub)disciplines: molecular/evolutionary ecology and genetics, ecology and economics, ecology and geology, ecology and paleontology, ecology and atmospheric deposition, ecology and climate regulation, ecology and environmental planning, and ecology and environmental quality (e.g., Dicke et al. 2011; Costanza et al. 1997; Dommain et al. 2011; Dunne et al. 2008; Elser et al. 2009; West et al. 2011; Taylor Lovell and Johnston 2009; Mulder et al. 2011, respectively). Although most attention is provided to pristine terrestrial biota and extreme environments (e.g., Bai et al. 2004; Yu et al. 2010), ecology provides the necessary knowledge to assess consequences of disturbance and stress, such as the effects of pollution, mining, and engineering on local communities at the landscape level (De Zwart et al. 2006; Dugan et al. 2010; Wang et al. 2010). Moreover, using several case studies from the Great Barrier Reef, Stoeckl et al. (2011) pointed out how important it is to differentiate between information about existing ecosystem services (Adhikari and Nadella 2011) and information about the extent to which existing ecosystem services might change (or have already changed) in response to external events (West et al. 2011).

\section{The world of science changed radically}

Science is at a tipping point at which research will rapidly become more applied. Land conversion for agriculture is projected to rise sharply (Laurance 2001), and strong empirical evidence is available. Thanks to the huge increase in peer-reviewed publications, ecology helps in understanding what is going on, in sustaining current ecosystems and in managing novel ecosystems, and contributes in the societal thought process. Indeed, nobody is questioning that the entire world of science 


\section{All Scientific Data Online}

\section{- Many disciplines overlap and use data from other sciences}

- Internet can unify all literature and data

- Go from literature to computation to data back to literature

\section{- Information at your fingertips for everyone-everywhere}

Derived and Recombined Data

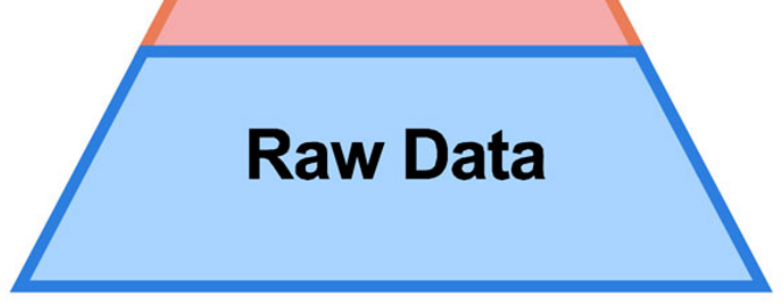

- Increase Scientific Information Velocity

- Huge increase in Science Productivity

Figure 1 eScience is about global collaboration: a world where data and literature interoperate with each other. (Adapted from Hey and Trefethen 2003; Henzinger and Lawrence 2004, and references therein; photo credit by Hey et al. 2009; free eBook at http://fourthparadigm. org, courtesy of Microsoft Research.).

has changed (Laurance 2001; Hey et al. 2009). From this perspective, open-access journals (ranging from cosmology to environment and from medicine to biology) are for sure the best way to share empirical data, models, and thoughts with others (Bourne et al. 2008; Figure 2). Successful linking of (e)Science with decision making will depend on accuracy and communication (Clark et al. 2001).

Balancing theory and empirical data at different levels allowed a shift in the scientific inquiries, resulting in an improved performance of current investigation. (Previously, a myriad of topics made navigation more difficult.) Internet, networking, international programs, and the astonishingly high amount of data confluence into this new conceptual framework (Hey et al. 2009), where any traditional (sub)discipline has been forced to change (see Box 1 and references therein; Mulder et al. 2011). Internet can unify such (sub)disciplines in a fractal-like world with increasing complexity and accessible detail (Figure 2), demonstrating the need to unify philosophy of science with the science and technology studies.
Albeit some ecologists seem not to be fully aware of the enhancements of online scholarly communication, open access is really beginning to spread. Still, only one-fourth of the contributions published between 2003 and 2010 by the Public Library of Science [PLoS] (2011) belong to the categories Development and Evolutionary Biology, Ecology, Marine and Aquatic Sciences, or Plant Biology, and less than $0.15 \%$ of the seven hundreds of thousand contributions deposited during the same period in the arXiv (2011) belong to the 'Quantitative Biology' category. Seeing how many ecologists appreciate PLoS (and open access in general), these relatively low contributions surprise me. Something comparable occurs with data sharing: empirical data sets are of the highest value (cf. Bourne 2005), but ecologists seem to become 'shy' when asked to make their data accessible. This makes me question why in 2010, only $7 \%$ of all the participants to one EU-funded project responded to their open data call?

This short overview shows, on the one hand, how many ecologists are already dealing with data sharing and eScience, and on the other hand, how different complementary frameworks seem to coexist. The 


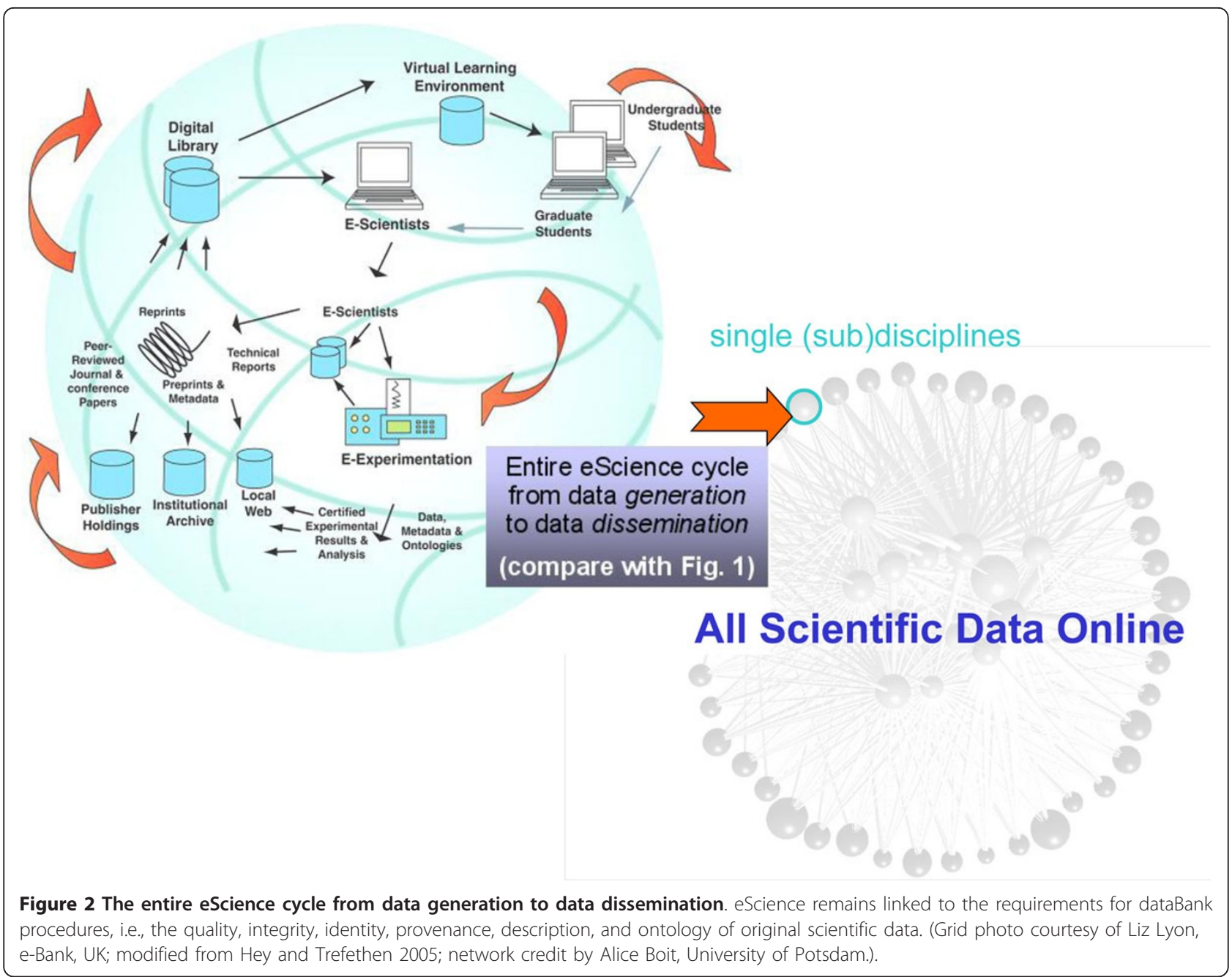

overlap between schools and frameworks can be rather confounding. For instance, although many features are common to different ways of performing research, metadata focusing on compiled information for local communities are widespread as ecological networks, whereas scientific data derived from simulated or empirical information are commonly defined as food webs. This implies that webs can, in most cases, be seen as networks although not all ecological networks may be seen as traditional food webs. However, in contrast to many nested networks, eScience is mutual and, as such, is expected to grow with vigor because, in contrast to (antagonistic) living organisms, eScience has no discrete boundaries but has digitally cross-connected domains with high modularity.

\section{Thinking seriously about the scenario}

After all the efforts of producing a research paper (from laboratory and/or field work up to forecasting, networking, feedbacks, and final writing), how are ecologists currently thinking about their outreach? Bourne (2010) provocatively wrote that in contrast to the rather static PDF interface, publishing workflows - and preprint repositories and postpublication commentaries can be seen as a kind of creative workflows - are more powerful but harder to manage and represent, therefore, a major change for most scientists.

Apparently, ecologists belong to those scientists, but if they are not able to keep online the attention of their own colleagues, then how can they expect any concrete feedbacks from environmentally interested laypersons and policy decision makers? How can stakeholders expect a concrete use of ecological indicators if most scientists dealing with such an integrative discipline seem to (be willing to) ignore a large part of data and recent literature on environmental impact and ecosystem services ( $c f$. Bjorndal et al. 2011)?

Having seen these disputes between institutions, it is not a wonder that Al Gore has succeeded in areas where so many scientists, stakeholders, and NGOs have failed. It is time for a radical departure; to improve the 
synergy between authors, publishers, and readers, two possible incentives should be considered as novel opportunities:

- Be explicit and do not try to be exhaustive There is an increasing amount of review papers cited to support empirical data, and most results can be interesting for a wide variety of scientists if the original results could be put in a much wider context. Most manuscripts just aim to bridge knowledge gaps, but overwhelming references are always inappropriate to catch real attention, and chains of citations have to be avoided as they move from journal to journal (Hirsch 2005). We should strive to generate less academic papers and attempt to sample the web uniformly.

- Be wide and do not claim something else Bibliographic couplings aim to identify structures and communities (Menczer 2004). To avoid strong discipline bias, take substantial precaution. Do not claim shocking lack of knowledge (such terms are not objective) and do not cite only the papers that seem to confirm your results (Jennions and Møller 2002). Your literature shows your horizons. In the framework of eScience, papers always benefit from testing the theory or hypothesis regarding how relationships change, so be wide in the chosen references.

Let us put matters straight: ecological forecasts are imperative (Clark et al. 2001). These authors defined ecological forecasting as 'the process of predicting the state of ecosystems, ecosystem services, and natural capital' (Clark et al. 2001). Although some scientists still prefer to claim that no data are available to specify uncertainties or find that novel ideas cannot be tested properly for lack of appropriate technology ( $c f$. Collins 2010), others state that larger data sets (inclusive historic data sets) are meanwhile discoverable (Hunt et al. 2009), making ecological forecasting feasible. Data are interwoven with peer-reviewed scientific papers, are authored in digital form, and are benefits of today's structural use of the entire digital environment (Lynch 2009).

\section{A new scientific endeavor online}

As a matter a fact, 'science aims to produce far more than a simple mechanical prediction of correlations' (Ginsparg 2009), and most open-access journals clearly aim to support a better comprehension of the exabytes of already available information and to improve strongly the dissemination of data, causalities, and implications. Therefore, Ecological Processes is governed by three principles: research quality, multidisciplinarity and integration, and open access. (Overarching principles are reflected by all those who have agreed to provide part of their precious time as committed editors.) As editors in chief, we all have plenty of ideas for what Ecological Processes means, but we really wish to get your input too, as you like it.

Received: 24 May 2011 Accepted: 10 February 2012

Published: 10 February 2012

\section{References}

Adhikari B, Nadella K (2011) Ecological economics of soil erosion: a review of the current state of knowledge. Ann New York Acad Sci 1219:134-152

Allesina S, Pascual M (2009) Googling food webs: can an Eigenvector measure species' importance for coextinctions? PLoS Comput Biol 5(9):e1000494

arXiv (2011) Cornell University Library, Ithaca, NY http://arxiv.org. Accessed 20 Apr 2011

Bai Y, Han X, Wu J, Chen Z, Li L (2004) Ecosystem stability and compensatory effects in the Inner Mongolia grassland. Nature 431:181-184

Bjorndal KA, Bowen BW, Chaloupka M, Crowder LB, Heppell SS, Jones CM, Lutcavage ME, Policansky D, Solow AR, Witherington BE (2011) Better science needed for restoration in the Gulf of Mexico. Science 331:537-538

Bollen J, Van de Sompel H, Hagberg A, Chute R (2009) A principal component analysis of 39 scientific impact measures. PLOS ONE 4(6):e6022

Bourne P (2005) Will a biological database be different from a biological journal? PLoS Comput Biol 1(3):e34

Bourne PE (2010) What do I want from the publisher of the future? PLoS Comput Biol 6(5):e1000787

Bourne PE, Fink JL, Gerstein M (2008) Open access: taking full advantage of the content. PLoS Comput Biol 4(3):e1000037

Clark JS, Carpenter SR, Barber M, Collins S, Dobson A, Foley JA, Lodge DM, Pascual M, Pielke R Jr, Pizer W, Pringle C, Reid WV, Rose KA, Sala O, Schlesinger WH, Wall DH, Wear D (2001) Ecological forecasts: an emerging imperative. Science 293:657-660

Cohen JE (2004) Mathematics is biology's next microscope, only better; biology is mathematics' next physics, only better. PLoS Biol 2(4):e439

Collins JP (2010) Sailing on an ocean of Os and 1s. Science 327:1455-1456

Costanza R, D'Arge R, De Groot R, Farber S, Grasso M, Hannon B, Limburg K, Naeem S, O'Neill RV, Paruelo J, Raskin RG, Sutton P, Van den Belt M (1997) The value of the world's ecosystem services and natural capital. Nature 387:253-260

De Gouw JA, Middlebrook AM, Warneke C, Ahmadov R, Atlas EL, Bahreini R, Blake DR, Brock CA, Brioude J, Fahey DW, Fehsenfeld FC, Holloway JS, Le Henaff M, Lueb RA, McKeen SA, Meagher JF, Murphy DM, Paris C, Parrish DD, Perring AE, Pollack IB, Ravishankara AR, Robinson AL, Ryerson TB, Schwarz JP, Spackman JR, Srinivasan A, Watts LA (2011) Organic aerosol formation downwind from the Deepwater Horizon oil spill. Science 331:1295-1299

De Zwart D, Dyer SD, Posthuma L, Hawkins CP (2006) Predictive models attribute effects on fish assemblages to toxicity and habitat alteration. Ecol Appl 16:1295-1310

Dicke M, Van Loon JJA, De Jong PW (2011) Ecogenomics benefits community ecology. Science 305:618-619

Dommain R, Couwenberg J, Joosten H (2011) Development and carbon sequestration of tropical peat domes in south-east Asia: links to post-glacial sea-level changes and Holocene climate variability. Quater Sci Rev 30:999-1010

Dugan PJ, Barlow C, Agostinho AA, Baran E, Cada GF, Chen D, Cowx IG, Ferguson JW, Jutagate T, Mallen-Cooper M, Marmulla G, Nestler J, Petrere M, Welcomme RL, Winemiller KO (2010) Fish migration, dams, and loss of ecosystem services in the Mekong basin. Ambio 39:344-348

Dunne JA, Williams RJ, Martinez ND, Wood RA, Erwin DH (2008) Compilation and network analyses of Cambrian food webs. PLoS Biol 6(4):e102

Elser JJ (2006) Biological stoichiometry: a chemical bridge between ecosystem ecology and evolutionary biology. Am Nat 168:S25-S35

Elser JJ, Andersen T, Baron JS, Bergström A-K, Jansson M, Kyle M, Nydick KR, Steger $L$, Hessen DO (2009) Shifts in lake N:P stoichiometry and nutrient limitation driven by atmospheric nitrogen deposition. Science 326:835-837

Ginsparg P (2009) Scholarly communication. In: Hey T, Tansley S, Tolle K (ed) The fourth paradigm: data-intensive scientific discovery. Redmond, Microsoft Research, 185-191 
Grimm NB, Grove JM, Pickett STA, Redman CL (2000) Integrated approaches to long-term studies of urban ecological systems. BioScience 50:571-584

Haldane AG, May RM (2011) Systemic risk in banking ecosystems. Nature 469:351-355

Henzinger M, Lawrence S (2004) Extracting knowledge from the World Wide Web. Proc Natl Acad Sci USA 101:5186-5191

Hey T, Trefethen A (2003) e-Science and its implications. Phil Trans R Soc Lond A 361:1809-1825

Hey T, Trefethen A (2005) Cyberinfrastructure for e-Science. Science 308:817-821

Hey T, Tansley S, Tolle K (eds) (2009) The fourth paradigm: data-intensive scientific discovery. Microsoft Research, Redmond,

Hirsch JE (2005) An index to quantify an individual's scientific research output. Proc Natl Acad Sci USA 102:16569-16572

Hunt JR, Baldocchi DD, Van Ingen C (2009) Redefining ecological science using data. In: Hey T, Tansley S, Tolle K (ed) The fourth paradigm: data-intensive scientific discovery. Microsoft Research, Redmond, 21-26

Jennions MD, Møller AP (2002) Publication bias in ecology and evolution: an empirical assessment using the 'trim and fill' method. Biol Rev 77:211-222

Laurance WF (2001) Future shock: forecasting a grim fate for the Earth. Trends Ecol Evol 16:531-533

Lynch C (2009) Jim Gray's fourth paradigm and the construction of the scientific record. In: Hey T, Tansley S, Tolle K (ed) The fourth paradigm: data-intensive scientific discovery. Microsoft Research, Redmond, 177-183

Menczer F (2004) Evolution of document networks. Proc Natl Acad Sci USA 101:5261-5265

Mulder C, Boit A, Bonkowski M, De Ruiter PC, Mancinelli G, Van der Heijden MGA, Van Wijnen HJ, Vonk JA, Rutgers M (2011) A belowground perspective on Dutch agroecosystems: how soil organisms interact to support ecosystem services. Adv Ecol Res 44:277-357

Naeem S, Bunker DE, Hector A, Loreau M, Perring CP (eds) (2009) Biodiversity, ecosystem functioning, and human wellbeing. Oxford University Press, Oxford

Pimentel D, Bailey O, Kim P, Mullaney E, Calabrese J, Walman L, Nelson F, Yao X (1999) Will limits of the Earth's resources control human numbers? Environ Dev Sustain 1:19-39

PLoS (2011) Public Library of Science, San Francisco, CA http://www.plos.org. Accessed 20 Apr 2011

Schiermeier Q (2011) Radiation release will hit marine life. Nature 472:145-146

Sjögren P, Lamentowicz M (2008) Human and climatic impact on mires: a case study of Les Amburnex mire, Swiss Jura Mountains. Veg Hist Archaeobot 17:185-197

Stoeckl N, Hicks CC, Mills M, Fabricius K, Esparon M, Kroon F, Kaur K, Costanza R (2011) The economic value of ecosystem services in the Great Barrier Reef; our state of knowledge. Ann New York Acad Sci 1219:113-133

Taylor Lovell S, Johnston DM (2009) Creating multifunctional landscapes: how can the field of ecology inform the design of the landscape? Front Ecol Environ 7:212-220

United Nations Population Division (2010) World population prospects. http://esa. un.org/unpd/wpp/index.htm. Accessed 18 Jan 2012

Van Straalen NM (2003) Ecotoxicology becomes stress ecology. Environ Sci Technol 37:324A-330A

Wang J, Huang J, Wu J, Han X, Lin G (2010) Ecological consequences of the Three Gorges Dam: insularization affects foraging behavior and dynamics of rodent populations. Front Ecol Environ 8:13-19

West PC, Narisma GT, Barford CC, Kucharik CJ, Foley JA (2011) An alternative approach for quantifying climate regulation by ecosystems. Front Ecol Environ 9:126-133

Yu Q, Chen Q, Elser JJ, He N, Wu H, Zhang G, Wu J, Bai Y, Han X (2010) Linking stoichiometric homeostasis with ecosystem structure, functioning, and stability. Ecol Lett 13:1390-1399

Zu Dohna H, Cecere MC, Gürtler RE, Kitron U, Cohen JE (2009) Spatial reestablishment dynamics of local populations of vectors of Chagas disease. PLoS Negl Trop Dis 3(7):e490

doi:10.1186/2192-1709-1-1

Cite this article as: Mulder: Ecology and eScience. Ecological Processes 2012 1:1.

\section{Submit your manuscript to a SpringerOpen ${ }^{\mathcal{O}}$ journal and benefit from:}

- Convenient online submission

- Rigorous peer review

- Immediate publication on acceptance

- Open access: articles freely available online

- High visibility within the field

- Retaining the copyright to your article

Submit your next manuscript at $\gg$ springeropen.com 